\title{
REPRESENTAÇÃO ESPACIAL DA COBERTURA VEGETAL NATURAL ORIGINAL DO MUNICÍPIO DE SÃO JOSÉ DOS CAMPOS (SP)
}

\author{
Ademir Fernando Morelli ${ }^{1}$ \\ Felisberto Cavalheiro ${ }^{3}$ \\ MarCello AlVEs ${ }^{2}$ \\ MarCel Fantin $^{2}$
}

${ }^{1}$ Universidade de Taubaté - Departamento de Engenharia Civil e Ambiental - DECA

R. Expedicionário Ernesto Pereira, 99 - Centro - Taubaté (SP) CEP 12020-230

afmorelli@unitau.br

${ }^{2}$ Universidade do Vale do Paraíba - Instituto de Pesquisa e Desenvolvimento - IPD

Av. Shishima Hifumi, 2911 - Urbanova - São José dos Campos (SP) CEP 12244-000

(mfantin, malves) dunivap.br

\begin{abstract}
${ }^{3}$ Universidade de São Paulo - Departamento de Geografia - FFLCH
R. Prof. Lineu Prestes, 338 - Butantã - São Paulo (SP) CEP 05508-900
\end{abstract}

felis@usp.br

\section{Resumo}

O objetivo deste trabalho foi inferir a configuração da cobertura vegetal natural original da paisagem do município de São José dos Campos. A paisagem do município conta com quase 500 anos de ocupação, encontra-se altamente fragmentada e com um número significativo de áreas em diferentes níveis de degradação. A Configuração original é fundamental para a recuperação, definindo o tipo de formação vegetal a ser recuperada para cada local específico. Os procedimentos metodológicos basearam-se nos conceitos teóricos e metodológicos da Ecologia da Paisagem e de Restauração e sua aplicação na avaliação do modelo de ambiente ecológico de cada formação vegetal, sendo empregados dados e técnicas de Sensoriamento Remoto, Geoprocessamento, GPS e de trabalhos de campo. Os resultados indicam que a paisagem original do município de São José dos Campos, como encontrada no século XVI pelos primeiros colonizadores era composta por sete tipos principais de formações vegetais, 
dos biomas de Mata Atlântica e de Savana: FESMar-Floresta Estacional Semidecidual Montana nos Planaltos interioranos da Serra do Mar; FESA - Floresta Estacional Semidecidual Aluvial nas Várzeas do Rio Paraíba do Sul; FESMant-Floresta Estacional Semidecidual nos morros Interioranos da Serra da Mantiqueira; FODM-Floresta Ombrófila Densa Montana e Alto Montana nas Escarpas da Serra da Mantiqueira; FOMAM-Floresta Ombrófila Mista Alto-Montana nas Escarpas da Serra da Mantiqueira; SAA-Savana Arbórea Aberta nas Colinas Tabuliformes do Vale do Paraíba do Sul. O principal resultado foi o mapa da cobertura vegetal natural original do município na escala 1:25.000, representando espacialmente as formações vegetais originais. As contribuições principais deste trabalho foram: a) Considerar os processos históricos da Paisagem; b) Estruturar uma forma para uma abordagem espacial da história da paisagem; c). Determinar a configuração e os tipos de formação vegetal da paisagem original; d) Auxiliar na determinação da contingência (condições específicas que influenciam um local) e e) Determinar os parâmetros referenciais para um modelo de recuperação de áreas degradadas, segundo os princípios da Ecologia da Restauração.

Palavras-chave: história da paisagem; sensoriamento remoto; geoprocessamento; São José dos Campos

\begin{abstract}
The objective of this work was to infer the Configuration of the original natural vegetable covering. The methodological procedures based on the theoretical and methodological concepts of the Landscape Ecology and its application in the evaluation of the model of ecological environment for every vegetal formation, being used the data and the techniques of Remote Sensing, Geoprocessing and of field works.The original landscape of São José dos Campos municipality, as found in the century XVI by the first settlers, it was composed by seven main types of vegetation formations belonging to the biomas of the Atlantic forest and of the Savannah: FESMar-Floresta Estacional Semidecidual Montana nos Planaltos Interioranos da Serra do Mar; FESA- Floresta Estacional Semidecidual Aluvial nas Várzeas do Rio Paraíba do Sul; FESMant-Floresta Estacional Semidecidual Montana nos Planaltos Interioranos da Serra do Mantiqueira; FODM-Floresta Ombrófila Densa Montana e Alto Montana nas Escarpas da Serra da Mantiqueira; FOMAM-Floresta Ombrófila Mista AltoMontana nas Escarpas da Serra da Mantiqueira; SAA-Savana Arbórea Aberta nas Colinas
\end{abstract}


Tabuliformes do Vale do Paraíba do Sul. The main contributions of this work were to consider the Landscape as historical document; to investigate the historical use of the landscape; to use the data and techniques of Remote Sensing and Geoprocessing in the historical investigation; and to structure a procedure for a space approach in the history of the landscape.

Keywords: landscape history; landscape ecology; remote sensing; geoprocessing; São José dos Campos

\section{Introdução}

A paisagem do município de São José dos Campos apresentava originalmente a expressão concreta e espacial dos ecossistemas que o compunham.

Aspectos como extensão em área (com $1.102 \mathrm{~km}^{2}$ e um dos maiores municípios do Estado de São Paulo), localização e posicionamento do município em relação ao Vale do Paraíba (transversal ao Vale - sentido de maior variabilidade das características ambientais) condicionam o município a ter alto índice de heterogeneidade ambiental, física e biológica. Fisicamente, compreende desde os Morros da Serra do Mar, a transição dos morros cristalinos desta Serra, até as Colinas Tabuliformes (terraços fluviais) e destas até a Várzea do Rio Paraíba do Sul e, novamente, a passagem por colinas e morros até encontrar as Escarpas da Serra da Mantiqueira, (com uma variação altitudinal de até $1500 \mathrm{~m}$ ). Biologicamente, ocorrendo a Floresta Ombrófila Densa Montana e Alto-Montana e a Floresta Ombrófila Mista nas escarpas da Serra da Mantiqueira, a Floresta Estacional Semidecidual Montana, nos morros da Serra do Mar e da Mantiqueira, a Floresta Estacional Semidecidual Aluvial, nas várzeas do Rio Paraíba do Sul e de seus afluentes e enclaves típicos de Savana Arbórea Aberta nas colinas tabuliformes (Ab'Saber,1965, p. 199), constituindo ecótones com altíssima biodiversidade florística e faunística (IBGE, 1988, 1992).

Esta condição de excepcionalidade é demonstrada por ser o Vale do Paraíba, conforme Mittermeier et al. (2000), um dos oito "hot spots" (áreas mais quentes em diversidade de espécies) do planeta em termos de biodiversidade.

Entretanto, a paisagem que herdamos de São José dos Campos, apesar de incorporar a história da sociedade que a transformou em patrimônios culturais vários (ambiental, arquitetônico, histórico), encontra-se bastante alterada nas suas características originais, 
estando ameaçadas de desaparecer pelas atividades humanas. Por exemplo, dos ecossistemas naturais originais (a Mata Atlântica e o Cerrado) restam apenas fragmentos, que compreendem, segundo dados oficiais do Departamento Estadual de Proteção dos Recursos Naturais (DEPRN), quatorze por cento da área total do município (Kronka, 1993) e que estão ameaçados de destruição pela urbanização e pela ausência de políticas públicas e estratégias de conservação. Cabe ressaltar que os campos cerrados, vegetação original do local onde se assentou a vila de São José e que deu origem ao seu topônimo, são os ecossistemas mais ameaçados no município pelo próprio processo de urbanização da cidade que lhe empresta o nome.

\section{Objetivos}

2.1. Objetivo geral: representar espacialmente a configuração da cobertura vegetal natural original (Século XVI);

\subsection{Objetivos específicos:}

a) determinar o modelo teórico da configuração da vegetação original;

b) determinar os parâmetros ambientais das formações vegetais;

\section{Material e Métodos}

\subsection{Material}

Para a execução do trabalho foram disponibilizados produtos de sensoriamento remoto, material cartográfico e equipamentos afins.

\subsubsection{Imagens Orbitais e Fotografias aéreas}

Para a extração das informações espaciais sobre a cobertura vegetal e uso da terra foram utilizadas as seguintes fotografias aéreas e imagens de satélite:

a) Fotografias aéreas pancromáticas na escala 1:25.000, obtidas através de levantamento aerofotogramétrico em 1939, 1953, 1962, 1972 e 1985;

b) Fotografias aéreas coloridas, obtidas através do levantamento aerofotogramétrico realizado pelo INPE, na escala 1:10.000 em 1997;

c) Imagens digitais TM/Landsat 5, órbita 234, ponto 76, bandas 3 (vermelho - 0,63 a 0,69 ๆm), 4 (Infravermelho próximo - 0,76 a 0,90 ๆm) e 5 (Infravermelho Médio 1,55 a 1,75 ๆm), resolução espacial de $30 \mathrm{~m}$, data de 28 de setembro de 1998;

d) Imagens digitais PAN/HRV/Spot 2, órbita 718, ponto 396, (visível e Infravermelho próximo - 0,510 a 0,730 ๆm), com resolução espacial de 10m e XS/HRV/Spot 2 
Verde $(0,500$ a $0,590 \eta \mathrm{m})$, Vermelho $(0,610$ a $0,680 \eta \mathrm{m})$ e Infravermelho próx. $(0,790$ a 0,890 ๆm) com resolução espacial de 20m, obtidas em 02/set/98.

\subsubsection{Material Cartográfico}

Para a formação da base cartográfica e o georreferenciamento das informações temáticas foram utilizados os seguintes materiais cartográficos:

a) Cartas topográficas do Plano Cartográfico do Estado de São Paulo na escala $1: 10.000$

b) Carta do uso da terra do Município de São José dos Campos, escala 1:100.000, 1987, Projeto AUTES - Atualização do Uso da Terra no Município de São José dos Campos - (INPE-PMSJC, 1987)

c) Cartas de Cobertura Vegetal e Uso da Terra, Levantamento de Solos, Geomorfológico, Hipsométrico, Macrozoneamento, realizado pelo Projeto MAVALE - Macrozoneamento do Vale do Paraíba e Litoral Norte do Estado de São Paulo (Kurkdjian et al., 1992);

d) Carta geotécnica do Município de São José dos Campos, escala 1:50.000, 1996 (IPT, 1996);

e) Carta de Cobertura Vegetal Natural do Projeto RADAMBRASIL na escala 1:1.000.000 (Brasil, 1986).

\subsubsection{Material histórico "não-espacial"}

a) Informações Cartoriais (escrituras e inventários de propriedades);

b) Relatórios dos Presidentes de Províncias do século XIX, contendo dados de produção de café, das propriedades rurais e de suas benfeitorias;

c) Fotografias antigas do acervo do Arquivo Público Municipal de São José dos Campos.

\subsubsection{Equipamentos}

Para a entrada, organização e saída das informações do projeto foram utilizados:

a) Estações de trabalho e micro padrão IBM/PC-Pentium III $800 \mathrm{MHz}$, instalada com o SIG (Sistema de Informação Geográfica) SPRING (Sistema de Processamento de Informações Georreferenciadas), (INPE, 2000); 
b) Computador portátil instalado com o programa GTM PRO ${ }^{\circledR}$, utilizado para navegação e orientação em campo;

c) Sistema de Posicionamento Global (GPS) modelo Garmin SRV II;

d) Estereoscópios de espelho marca Wild para auxiliar interpretação das fotografias aéreas;

\subsection{Metodologia}

\subsubsection{Revisão de Literatura e Levantamento de Dados}

Foram interpretados o material cartográfico existente (cartas topográficas e mapas temáticos) e os dados espaciais de sensoriamento remoto (fotografias aéreas e imagens orbitais) sobre a área de estudo. A coleta de dados compreendeu ainda o levantamento de informações históricas, relatos dos naturalistas, informações cartoriais e de documentos históricos e Relatórios dos Presidentes de Províncias do século XIX.

\subsubsection{Interpretação das informações históricas}

As informações históricas relacionadas à paisagem original foram interpretadas e transpostas à base de dados para a determinação de sua configuração original.

\subsubsection{Seleção do sistema de classificação da vegetação natural}

A caracterização das formações vegetais, baseou-se na classificação oficial adotada pelo IBGE no Mapa de Vegetação do Brasil (IBGE, 1988). O sistema de classificação fisionômico-ecológico, adotado pelo IBGE, de acordo com os mais modernos sistemas internacionais de classificação tem sido utilizado, independentemente da escala de mapeamento, principalmente pela ausência de estudos florísticos e fitossociológicos mais detalhados e tem sido aplicado como parâmetro na Legislação Ambiental.

Este trabalho considera essa questão da escala, emprega o sistema de classificação do IBGE, pelo método adotado no estudo da cobertura vegetal pretérita, mas reconhece a necessidade de estudos mais detalhados e complementares, que não puderam ser realizados neste trabalho por limitações técnicas e, sobretudo, de tempo.

\subsubsection{Determinação do modelo da configuração da vegetação original}

Empregou-se um modelo teórico da configuração da vegetação original baseado na compartimentação dos ambientes de cada formação, partindo-se do princípio ecológico de 


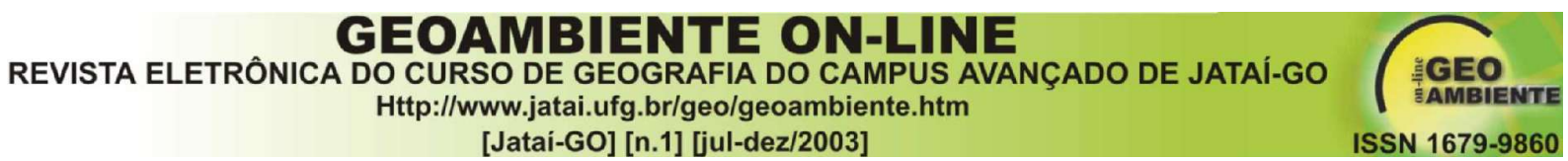

que, não tendo sido alterados irremediavelmente, os ambientes ainda refletiriam em sua maioria a vegetação natural primitiva.

Assim, os parâmetros ambientais de cada formação vegetal foram determinados pela integração das informações constantes nas cartas de vegetação e nos parâmetros de mapeamento da cobertura vegetal original adotados pelo IBGE no Mapa de Vegetação do Brasil (IBGE, 1988) e empregados no projeto RADAMBRASIL (Brasil, 1983).

Aplicaram-se os parâmetros ambientais da vegetação na escala de mapeamento de 1:50.000. As informações do mapa de vegetação na escala 1:250.000 foram transpostas à base de dados na escala 1:50.000, baseando-se nos parâmetros ecológicos de seu mapeamento original, mas empregando-se esses fatores com as informações do suporte da paisagem disponíveis na escala 1:50.000, produzidas por Morelli (2002).

\subsubsection{Determinação dos parâmetros ambientais das formações vegetais}

Os parâmetros das formações vegetais compreendem a conjugação de fatores geológicos, pedológicos, geomorfológicos e climáticos, na escala 1:250.000, que caracterizam os ambientes ecológicos de cada formação vegetal.

Posteriormente, a partir da integração do mapa de vegetação do IBGE para o Município, dos registros da literatura, dos mapas de uso da terra (1953 e 2000) e dados de campo, foram elaborados parâmetros ecológicos mais específicos para a vegetação do município. Os parâmetros foram checados em campo com os remanescentes de cada formação vegetal, com as toponímias (nome dos sítios, rios e demais localidades que estão relacionados às características originais do local) e também comparados com as observações da literatura, principalmente na descrição dos viajantes naturalistas Auguste de Saint-Hilaire (1974 e 1976), Johan Baptist von Spix, Carl Friedrich von Martius ( Spix \& Martius, 1976), Johan Moritz Rugendas e Augusto Emilio Zaluar (Zaluar, 1953).

\subsubsection{Compartimentação esquemática para os ambientes de cada formação} vegetal

Baseando-se no modelo de geração da cobertura vegetal natural, propôs-se uma compartimentação esquemática geral para os ambientes de cada formação vegetal. Procurouse mostrar a integração dos parâmetros ecológicos que condicionam os ambientes e conseqüentemente a vegetação, especificando-se as classes de subformação vegetal natural para o município. 


\subsubsection{Geração do Mapa de Cobertura Vegetal Natural original}

No módulo de análise espacial do SPRING, baseando-se no mapa de compartimentação física da paisagem (Morelli, 2002) para compor os parâmetros ambientais de cada formação, foi realizado o processo de integração AHP (Processo de Análise Hierárquica), resultando no mapa da cobertura vegetal natural.

A configuração da cobertura vegetal natural original foi obtida através da integração do mapa de unidades físicas da paisagem, realizado por Morelli (2002), e dos parâmetros ambientais de cada formação vegetal, conforme processos descritos no quadro 1 .

Quadro1 Processo de integração para a configuração original da paisagem

\begin{tabular}{|c|c|c|c|}
\hline FONTE & PROCESSO & TEMAS & PRODUTO \\
\hline $\begin{array}{l}\text { Parâmetros vegetação } \\
\text { IBGE }\end{array}$ & $\begin{array}{l}\text { Transposição } \\
\text { parâmetros } \\
\text { mapeamento IBGE }\end{array}$ & $\begin{array}{l}\text { Classes de formação } \\
\text { vegetação natural }\end{array}$ & $\begin{array}{l}\text { Mapa de vegetação } \\
\text { IBGE para o } \\
\text { Município }\end{array}$ \\
\hline Mapa de vegetação & Definição de & Parâmetros & Síntese para o \\
\hline IBGE para o Município & parâmetros ecológicos & ambientais para cada & modelo de geração \\
\hline Registros literatura & mais específicos para & formação vegetal & da cobertura \\
\hline $\begin{array}{l}\text { Mapas de uso da terra } \\
\text { Dados de campo }\end{array}$ & o município & & vegetal original \\
\hline Modelo de geração da & & & Compartimentação \\
\hline cobertura vegetal & ambientais da & subformação vegetal & esquemática geral \\
\hline natural & vegetação & natural & $\begin{array}{l}\text { para os ambientes } \\
\text { de cada formação } \\
\text { vegetal }\end{array}$ \\
\hline Compartimentação & Integração processo & Classes de Cobertura & Mapa da Cobertura \\
\hline esquemática geral para & AHP & vegetal natural & vegetal natural \\
\hline $\begin{array}{l}\text { os ambientes de cada } \\
\text { formação vegetal }\end{array}$ & & original & original \\
\hline Mapa de & & & \\
\hline $\begin{array}{l}\text { compartimentação } \\
\text { física da paisagem }\end{array}$ & & & \\
\hline
\end{tabular}

Fonte: Morelli, 2002. 


\section{Resultados e Discussão}

Inicialmente, exibem-se os parâmetros utilizados no mapeamento das formações vegetais e os mapas, gravuras e perfis esquemáticos que foram empregados para a configuração da cobertura vegetal natural original da paisagem. Posteriormente, apresentamse os dados gerados a partir do mapa da cobertura vegetal natural da paisagem original do Município.

\subsection{Os parâmetros das formações vegetais}

No município de São José dos Campos, seguindo a descrição dos parâmetros ambientais adotados por Radambrasil (Brasil, 1983), foi possível a reconstituição de sete ambientes relacionados às diferentes formações vegetais naturais ocorrentes na área:

\section{a) O ambiente da Savana Arbórea Aberta (SAA)}

Ocorre nas colinas tabuliformes, sobre os terrenos de cobertura pliocênica e pliopleistocênica da depressão periférica do médio Paraíba do Sul, cujos solos (Cambissolos + Latossolo Vermelho-Amarelo concrecionários, ambos álicos) são os principais fatores responsáveis pela sua ocorrência;

\section{b) O ambiente da Floresta Estacional Semidecidual Aluvial (FESA)}

As áreas sedimentares holocênicas dos terraços, formados por influência do rio Paraíba do Sul e seus afluentes, constituem os ambientes naturais que foram ocupados pela Floresta Estacional Semidecidual Aluvial. Ocorre sobre um clima tropical estacional com mais de 60 dias secos por ano;

c) O ambiente da Floresta Estacional Semidecidual Montana (FESMar) nas áreas colinosas do embasamento granítico e gnáissico do Paraíba do Sul e morros

As áreas colinosas, formadas pelo embasamento cristalino das serras do Mar (faixas de $600 \mathrm{a}$ $800 \mathrm{~m}$ ), que sofrem a influência de um clima estacional com mais de 60 dias secos, são os ambientes naturais onde ocorria a Formação Montana da Floresta Estacional Semidecidual.

d) O ambiente da Floresta Estacional Semidecidual Montana (FESMan) nas áreas de morros da Serra da Mantiqueira

Ocorre entre a feição geomorfológica de colina e o sopé dos espigões da Serra da Mantiqueira entre altitudes de 700 a 1000m, nos morros sobre embasamento granítico e gnáissico da Serra da Mantiqueira, no clima tropical estacional com mais de 60 dias secos; 
e) O ambiente da Floresta Ombrófila Densa Montana (FODM) nos morros e escarpas da Serra da Mantiqueira

Ocorre em altitudes que variam de 800 a 1500m, sobre embasamento granítico e gnáissico das escarpas da Serra da Mantiqueira, vertente voltada para o vale do Paraíba do Sul, que sofre influência da massa tropical marítima;

f) O ambiente da Floresta Ombrófila Densa Alto Montana (FODAM) nas escarpas da Serra da Mantiqueira

Ocorre na vertente da Serra da Mantiqueira, a partir do nível dos 1500m de altitude, sobre os Cambissolos do embasamento nas encostas desta serra. Ocupa normalmente os solos litólicos, que apresentam acumulações turfosas nas depressões fechadas;

\section{g) O ambiente da Floresta Ombrófila Mista Alto Montana (FOMAM) nos vales encravados nas escarpas da Serra da Mantiqueira}

Ocorre em ambiente caracterizado pelo embasamento cristalino de sua face interiorizada, em cotas altimétricas entre 1.400 e $1.800 \mathrm{~m}$, nos vales encaixados nas escarpas, onde a intensa atividade morfoclimática provocou um elevado grau de dissecamento. Ocorre nos anfiteatros de erosão e nas planícies fluviais, apresentando, nesta última situação topográfica, solos fundos e húmicos. O clima reinante nos ambientes de ocorrência apresenta-se como tropical ombrófilo de altitude, com chuvas relativamente bem distribuídas o ano inteiro.

\subsection{Compartimentação esquemática para os ambientes de cada formação vegetal}

Propôs-se uma compartimentação esquemática geral para os ambientes de cada formação vegetal. Procurou-se mostrar a integração dos parâmetros ecológicos que condicionam os ambientes e conseqüentemente a vegetação, especificando-se as classes de sub-formação vegetal natural para o município.

\subsection{Representação Espacial da Cobertura Vegetal Natural Original}

A figura 4.1 expõe o mapa da representação espacial da cobertura vegetal natural original da paisagem joseense.

É importante ressaltar que a delimitação das formações vegetais baseou-se na similaridade do conjunto de fatores do ambiente, atribuído a cada formação e que não representam os ecótones (áreas com sobreposição de duas formações vegetais) que ocorrem na paisagem do município. 
A paisagem original do município de São José dos Campos, como encontrada no século XVI pelos primeiros colonizadores, era composta por sete tipos principais de formações vegetais, dos biomas da Mata Atlântica e do Cerrado.

A tabela 1 apresenta os valores absolutos e relativos das áreas de cada formação vegetal natural original da paisagem do município de São José dos Campos.

As formações do bioma da Mata Atlântica dominavam a maior parte da paisagem original com $84 \%$ da área do município, sendo que a Floresta Estacional Semidecidual Montana dos Morros da Mantiqueira (FESMant) era a mais extensa com 45,87\%, seguida da Floresta Ombrófila Densa Montana dos Morros e Escarpas da Serra da Mantiqueira (FODM) com 13,88\%, da Floresta Estacional Semidecidual Aluvial (FESA) com 13,12\% e da Floresta Estacional Semidecidual dos Morros da Serra do Mar (FESMar) com 12,57\%.

O bioma do Cerrado ocorria na forma de enclaves representados pela Savana Arbórea Aberta (SAA) com 11,36\% do território. Em menor extensão, ocorriam as formações do bioma da Mata Atlântica, a Floresta Ombrófila Densa Alto-Montana (FODAM), com 2,25\%, e a Floresta Ombrófila Mista Alto-Montana (FOMAM), com 0,95\%.

Tabela 1 Valores absolutos e relativos das áreas das classes de formações vegetais originais (Séc XVI) para o município de São José Dos Campos

\begin{tabular}{|l|r|r|}
\hline Formações Vegetais & Área $\left(\mathrm{km}^{2}\right)$ & \multicolumn{1}{c|}{ Área (\%) } \\
\hline FESMant & 505,44 & $45,87 \%$ \\
\hline FODM & 152,93 & $13,88 \%$ \\
\hline FESA & 144,62 & $13,12 \%$ \\
\hline FESMar & 138,52 & $12,57 \%$ \\
\hline SAA & 125,21 & $11,36 \%$ \\
\hline FODAM & 24,83 & $2,25 \%$ \\
\hline FOMAM & 10,43 & $0,95 \%$ \\
\hline TOTAL & 1102,00 & $100,00 \%$ \\
\hline
\end{tabular}

Legenda: FESMar-Floresta Estacional Semidecidual Montana nos Planaltos Interioranos da Serra do Mar, FESA- Floresta Estacional Semidecidual Aluvial nas Várzeas do Rio Paraíba do Sul, FESMant-Floresta Estacional Semidecidual Montana nos Planaltos Interioranos da Serra do Mantiqueira, FODM-Floresta Ombrófila Densa Montana e Alto Montana nas Escarpas da Serra da Mantiqueira, FOMAM-Floresta Ombrófila Mista AltoMontana nas Escarpas da Serra da Mantiqueira, SAA-Savana Arbórea Aberta nas Colinas Tabuliformes do Vale do Paraíba do Sul.

Fonte: Morelli, 2002. 


\section{Conclusões}

Foi possível a determinação dos principais tipos de formações vegetais originais do Município e a quantificação de sua área original. O modelo de ambiente ecológico adotado para cada formação vegetal e os parâmetros ambientais propostos se adequaram e se mostraram compatíveis com os relatos dos naturalistas e com as evidências obtidas em campo, baseadas nos remanescentes das formações vegetais do Município.

No processo de integração AHP, no SIG Spring, foi possível a aplicação do esquema de compartimentação dos ambientes de cada formação vegetal e a determinação dos fatores condicionantes para cada formação: para a FESMar, FESA, FESMant e FOMAM, o relevo foi o principal fator, seguido do solo e da pluviosidade; para a SAA o fator solo foi o principal, seguido do relevo e pluviosidade; para as formações FODM e FODAM a pluviosidade, altitude e relevo foram os mais determinantes.

Observou-se alta similaridade entre os limites das unidades físicas e o das formações vegetais, refletindo a estreita relação observada na literatura e em campo entre os fatores relevo, variação altitudinal e pluviosidade para a configuração da cobertura vegetal original.

Apesar das limitações encontradas, ressalta-se a importância desta primeira aproximação dos tipos de formações vegetais do Município, pois o sistema fito-ecológico do IBGE (IBGE, 1993) é utilizado amplamente como parâmetro de proteção na legislação ambiental e pode auxiliar na determinação de estratégias e prioridades de conservação dos remanescentes para o Município.

Figura 1 Mapa da Representação Espacial da Vegetação Original de São José dos Campos 


\section{GEOAMBIENTE ON-LINE \\ REVISTA ELETRÔNICA DO CURSO DE GEOGRAFIA DO CAMPUS AVANÇADO DE JATAÍ-GO \\ Http://www.jatai.ufg.br/geo/geoambiente.htm}

[Jatai-GO] [n.1] [jul-dez/2003]

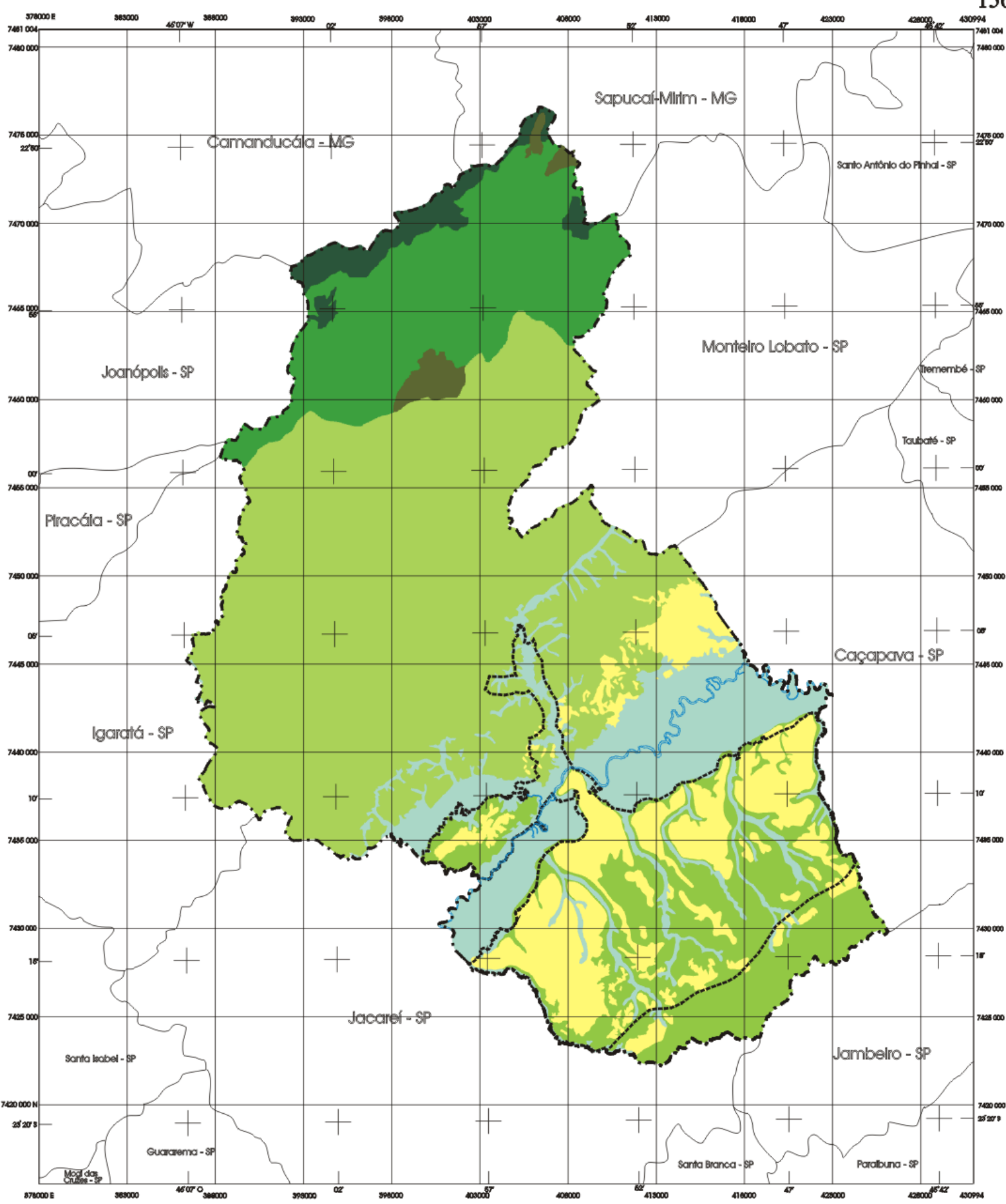

Convenções Cartográficas Legenda

Drenagem

hos Rio

$\measuredangle$ Ribeiräo/Córrego

Curso d'água intermitente

Represa/Barragem

- Lago/Lagoa

Estradas

$\measuredangle$ Estrada pavimentada

17 Estrada sem pavimentação

Caminho/trilha

$\square$ Estrada de Ferro

Limites

Limite Estadual

Limite Municipal

Limite Área Urbana

\section{Cobertura Vegetal Natural Original}

$\square$ Floresta Estacional Semidecidual Montana na S. Mar Flore sta Estacional Semidecidual Aluvial

Floresta Estacional Semide cidual Montana da S. Mant. Floresta Ombrófila Densa Montana na Serra da Mant. Floresta Ombrófila Densa Alto-Montana na S. da Mant. Floresta Ombrófila Mista Alto-Montana na S.na Mant. Savana Arbórea Aberta nas Colinas do Vale do Paraíba

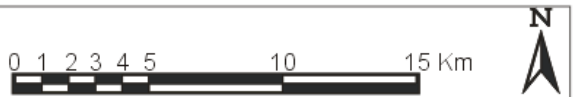

PROJEÇÄO UNIVERSAL TRANSVERSA DE MERCARTOR Fuso 23 - Meridiano Central 45

- CNG Minas Gerais Datum Vertic al: M arégrafo de Imbituba - Santa Catarina

\section{Nota de Crédito}

Base Cartográfica extraída das Cartas Topográficas do Plano Cartográico do Estado de São Paulo, na escala 1:10.000, obtidas a partir da restituição aer ofotogramétrica de aerofotos obtidas em 1977 pela empresa Terrafoto S/A na escala 1:10.000

Informaçỏes temátic as obtidas a partir da aplicação do modelo teórico da configuração da vegetação original baseado na compartimentação Jos a vegetais conforme a classificaça ão 


\section{Referências}

AB’SÁBER, Aziz Nacib. "Da participação das depressões periféricas e superfícies aplainadas na compartimentação do Planalto Brasileiro". Tese de Livre-Docência, FFCL USP. São Paulo, 1965.

BRASIL. "Projeto RADAMBRASIL - Folhas SF23/24 Rio de Janeiro e Vitória". IBGE, Rio de Janeiro, 1983.

BRASIL, "Mapa de vegetação do Brasil”. IBGE, Rio de Janeiro, 1986.

CARDOSO, M.F.T.C. Organização e reorganização do espaço no Vale do Paraíba do Sul Uma análise Geográfica até 1940. Rev. Bras. Geografia, Rio de Janeiro, 53(1):81-135, jan./mar.1991.

IBGE (Instituto Brasileiro de Geografia e Estatístico). Mapa de vegetação do Brasil. 1988. IBGE. Manual Técnico da Vegetação Brasileira. N. ${ }^{\circ}$ 1. IBGE: Rio de Janeiro, 1992.

INPE (Instituto Nacional de Pesquisas Espaciais) SPRING - Sistema de Processamento de Informações Georreferenciadas. http://www.dpi.inpe.br/spring. 2000.

INPE-PMSJC (Instituto Nacional de Pesquisas Espaciais - Prefeitura Municipal de São José dos Campos). Projeto Atualização do Uso da Terra no Município de São José dos Campos. 1987

IPT (Instituto de Pesquisas Tecnológicas). Carta Geotécnica do Município de São José dos Campos. São Paulo, IPT, 1996.

KRONKA, F; et al. "Inventário Florestal do Estado de São Paulo". IF: Instituto Florestal/SEMA, 1993.

KURKDJIAN, M.L.N.O. (Coord). Macrozoneamento do Vale do Paraíba e Litoral Norte do Estado de São Paulo. INPE. São José dos Campos, 1992.

MITTERMEIER, R.A., MYERS, Normal., MITTERMEIER, C.G., MYERS, Norman.

Hotspots: Earth's Biologically Richest and Most Endangered Terrestrial Ecoregions. Chicago, University of Chicago Press (Trd); 2000, (ISBN: 9686397582).

MORELLI, A.F. Identificação e Transformação das Unidades da Paisagem no Município de São José Dos Campos (SP) de 1500 a 2000. Rio Claro, 2002. 404 p. Tese (Doutorado em Geociências e Meio Ambiente) - Instituto de Geociências e Ciências Exatas de Rio Claro. 2002. Universidade Estadual Paulista "Júlio de Mesquita Filho". 
SAINT-HILAIRE, A. Viagem pelo distrito dos Diamantes e litoral do Brasil. Trad. Leonam de Azeredo Pena. Belo Horizonte, Ed. Itatiaia; São Paulo, Ed. da Univ. de São Paulo, 1974b. 233p. \{Reconquista do Brasil\}.

SAINT-HILAIRE, A. Segunda viagem do Rio de Janeiro a Minas Gerais e a São Paulo 1822. Trad. Vivaldi Moreira. Belo Horizonte, Ed. Itatiaia; São Paulo, Ed. da Univ. de São Paulo, 1974. 125p. (Reconquista do Brasil, 111).

SAINT-HILAIRE, A. Viagem a província de São Paulo. Trad. Regina Regis Junqueira. Belo Horizonte, Ed. Itatiaia; São Paulo, Ed. da Univ. de São Paulo, 1976. 229p. (Reconquista do Brasil, 18).

SPIX, J.B.; MARTIUS, C.F.P. VON. Viagens pelo Brasil: 1817-1820. 3.ed. Trad. Lúcia Furquim Lahmeyer. São Paulo, Melhoramentos; Brasília, Instituto Nacional do Livro, 1976. $3 \mathrm{v}$.

ZALUAR, Emílio. Peregrinação pela Província de São Paulo (1860-1861).Ed. Revista dos Tribunais, São Paulo, 1953, 236 p. 